\title{
lectureLess: A Mobile Cloud Computing Approach to Near Real-time Teach- ing Assessment
}

\section{Lt. Col. Steven J Henderson, U.S. Military Academy}

Lieutenant Colonel Steve Henderson is an Assistant Professor and Director, Systems Engineering/Operations Research Program at the United States Military Academy in West Point, NY. Steve holds a Ph.D. in Computer Science and has held a variety of Systems Engineering positions in academia and within the US Army.

\section{Dr. Kenneth McDonald, Dept of Systems Engineering, United States Military Academy, West Point}

Dr. McDonald is currently an Associate Professor of Engineering Management at the United States Military Academy at West Point and the Associate Director of the Center for Nation Reconstruction and Capacity Development. He has authored and co-authored over 20 technical publications to include book chapters and refereed publications on infrastructure, capacity development geotechnical engineering, engineering management, and value modeling.

Dr. McDonald earned his BS degree from the United States Military Academy in Civil Engineering (ABET), a MBA-Information Systems (Oklahoma City University); MS degrees in City and Regional Planning, Geography (Western Kentucky University) and Environmental Engineering (Missouri University of Science and Technology); and a PhD in Geological Engineering (Missouri School of Mines MS\&T). He is a registered Civil Engineer in the states of Virginia and Wyoming; he is a Certified Planner by the American Institute of Certified Planners (AICP); and a registered Project Management Professional (PMP) with the Project Management Institute (PMI). Dr. McDonald is also a member of Gamma Theta Upsilon and Phi Kappa Phi. His research and consulting interests are in capacity development analysis and decision analysis as applied to infrastructure and other complex enterprises especially in the arena of nation reconstruction and capacity development. He teaches classes in systems engineering, engineering economics, and project management. He has worked in Iraq, Afghanistan, Africa, and the Marshall Islands on a wide variety of economic development and assessment projects. 


\title{
lectureLess: A Mobile Cloud Computing Approach to Near Real-time Teaching Assessment
}

\begin{abstract}
In this paper, we introduce lectureLess, a mobile computing architecture designed to collect and manage near real-time learning assessment data reported by students. The goal of lectureLess is to leverage the ubiquitous nature of student mobile devices to monitor and collect self-reported learning trends as they occur during a typical classroom session. The system includes a mobile device application for the learner and a rich internet application for the teacher. The mobile device collects real-time feedback from students who use the mobile application to report attainment of three learning metrics: comprehension, motivation, and interaction. Assessment data is pushed into a cloud repository where it can be analyzed and projected to the teacher in near real-time or archived for analysis after class. We share our experiences with lectureLess as employed in two systems engineering courses taught by two different teachers. We include aggregate trends in overall student reporting and discuss the viability of mobile devices for near real-time assessment. We also include preliminary results from a pilot study linking self-reported trends in student learning to teaching techniques. In this study, we analyze assessment data from lectureLess and identify inflection points in the reported levels of comprehension, motivation and interaction. These inflection points are matched to corresponding video highlights of the assessed classroom session. The teacher then evaluates the video highlights and makes their own assessment about the students' attainment of the evaluated learning dimensions.
\end{abstract}

\section{Introduction}

In education, the role of the learner in their own education is fundamental and of much interest to the teacher. As we know from theories proposed by Bloom ${ }^{1}$, Perry ${ }^{2}$, and others, opportunities for the learner to participate in his or her education extend beyond simply receiving instruction. Rather, the richest experiences for learners are realized when they understand the very educational process they are a part of and are commissioned as equal and active partners in its execution. This higher form of learning requires the student to assess the educational process from their own perspective. This self-assessment not only includes the ability to gauge their understanding of particular topics, but also the ability to evaluate their own learning strategies and the current learning environment.

When the learner shares their self-assessment with the teacher, and the teacher reacts accordingly, a truly higher form of education is realized. This relationship is the motivation behind lectureLess, a mobile computing architecture that collects real-time learning assessment data from students and then presents this assessment to the teacher. The teacher can review the assessment data in near real-time and use this information in an ongoing classroom session. Additionally, the teacher can conduct a review after class and juxtapose the assessment data over the lesson plan to gain insights about what did and did not work for the students.

We believe several forces are combining to create opportunities for technologies like lectureLess to generate enhanced forms of student self-assessment. First, the majority of today's population of Millennials are avid social-networking participants ${ }^{3}$ who freely, regularly, and instantaneously report their feelings, thoughts, and opinions about nearly everything. We believe this behavior is 
creating a type of institutionalized assessment that implicitly contains elements of self-reflection. As such, educators have already begun integrating it into the classroom as evidenced in work by Yardi $^{4}$ and related work by Costa and colleagues ${ }^{5}$. Channeling social media behavior to include regular and candid feelings about student learning could create a powerful feedback mechanism in education. Second the ubiquity of powerful mobile computing devices, such as tablets and smart phones, provides a readily available and familiar platform for students. This platform can host applications to collect student self-assessment data either as an independent process or as part of other educational software.

In this paper, we begin with a review of related work and situate our contribution within these efforts. Next, we discuss the generalized learning assessment model we selected before engaging in a technological implementation. This includes discussing how the model supports a student-reported paradigm. We then introduce the lectureLess architecture which includes technical details about our design. Next, we describe a pilot study we conducted to examine the feasibility and general utility of the lectureLess approach. We describe some practical insights that we were able to derive using the tool and describe how these insights might be extendable into formal outputs. We conclude with some lessons learned and our plans for further research.

\section{Related Work}

Assessment of student learning is a well-researched field with many notable works. General research into the theory behind learning assessment includes a formal model for student selfassessment proposed by Pintrich and De Groot, which they correlated with student performance . $^{6}$ Research into the day to day assessment of learning includes the excellent compilation by Angelo and Cross that contains many practical learning assessment techniques. ${ }^{7}$ Fink's work emphasizes the importance of evaluating and assessing one's teaching from the perspective of the learner ${ }^{8}$, .

There has been much research conducted on the use of electronic devices or other technologies in the classroom for assessment purposes. This includes a voluminous body of work related to Audience Response Systems, also known as Student Response Systems, or "Clickers." This work is reviewed in separate surveys by Kay and LeSage ${ }^{10}$; Fies and Marshall ${ }^{11}$; and a previous comprehensive review by Caldwell ${ }^{12}$. In general, these systems present questions, in the form of polls with multiple choices, to students periodically throughout a class or lecture. Students then use specialized devices or interfaces to answer the question and the teacher (and entire class in some instances) is able to assess how well the students are grasping the material. These devices have been successfully incorporated directly into traditional lesson plans. More recent work features novel lesson designs explicitly built for incorporating the devices. Our approach differs from these previous efforts because our system monitors individual students continuously throughout the class (as opposed to all students collectively at discrete points in time) and our assessment directly measures the student perceptions about their learning (as opposed to their understanding of certain concepts).

Several recent works are more similar in either appearance or concept to our approach. Stav and colleagues employ iPods as a Student Response System ${ }^{13}$. This system uses a similar hardware platform as lectureLess. However, they also confine their system to asking discrete questions about subject material. Another system designed and implemented by Bry and colleagues establishes a digital backchannel for the teacher during each lesson ${ }^{14}, 15$. This backchannel is 
created using a microblogging service such as Twitter or Internet Relay Chat (IRC) to allow students to anonymously comment on the lecture during its progression. The system, known as Backstage, is similar in spirit to lectureLess in that it is designed to assess learning in real-time. Our system is different in that we collect the real-time data using a slightly structured assessment model where Backstage capture free form text comments.

Our principal contribution offered in lectureLess is it is the first system that we know of that leverages a freely available application on the student's own device to self-report on a simplified learning model in real-time. It also provides timely, accurate student feedback to the teacher on how effective the learning experience was for the student.

\section{Learning Assessment Model}

One of the greatest challenges a teacher faces concerns the student's reception of the class material as presented by the teacher. The teacher's effectiveness in the class cannot be determined without input by the student. The most effective way of getting feedback from students is to ask them. As easy as this sounds, it is much more problematic in practice. Timing is essential for accuracy. Anonymity is important to ensure students can relay their candid feedback to the teacher without the possibility of reprisal. Therefore it is important to get feedback while the teacher is conducting class and this can be found in a number of ways. As suggested by Highet ${ }^{16}$, a student's face is one of the best indications of how a presentation is being received. Essentially, students provide signals when a lecture is no longer working. As Lowman corroborates $^{17}$, yawns, chair shuffling, sighs, whispers, as well as glazed looks, crossed arms, leaning back away from desks are all physical messages that the teacher has lost the student and possibly the class. Teachers who have the keen ability to recognize these signs can adjust their techniques on the spot to better engage the students. Technologies and techniques that augment the perception of these cues would greatly benefit the vast majority of teachers.

Another technique to garner student feedback is to solicit it directly from them after class. This includes the collection of "minute papers" at the conclusion of class which ask students questions such as "What was the muddiest point during this lesson?" or "How would you improve this lesson if you were the teacher?" Angelo and Cross provide excellent coverage of these and other manual assessment techniques ${ }^{7}$. Such questions allow the teacher to understand where the students got lost or if there is a better way to present the material. A similar technique can be employed during class. As suggested by Lowman, asking questions such as "Can you hear me in the back row?"; "Am I going too fast?"; "Who can explain this concept in an easier way?"; etc all provide the teacher with an idea of how the class is receiving the material ${ }^{17}$.

Not only is asking questions important, but it is also necessary to ask the correct questions. One very famous study that emphasized this were the Dr. Fox experiments conducted by Naftulin and colleaugues $^{18},{ }^{19}$. In these experiments, Naftulin hired an actor to present a lecture to a group of educators. They named him Dr. Fox and mandated that he deliver the lecture in a highly expressive and entertaining manner. The lecture content had very little substantive content and had a large number of logical confusions and repetitions. The experimenters also gave the educators a fictitious Dr. Fox curriculum vita loaded with a number of publications. At the end of the lecture they asked the educators to rate Dr. Fox. The overall results were very favorable for Dr. Fox. One outcome of this experiment is the conclusion that student ratings are useless because lectures filled with "stuff" can persuade students into a positive view if the teacher is 
entertaining. Bain proposes that the Dr. Fox study had a major flaw - it asked the wrong questions $^{20}$. The Dr. Fox study asked simply asked if Dr. Fox did what he was instructed to do. None of the questions asked if the educators had learned anything. So it is important that not only does a teacher need timely and accurate student feedback, the teacher also needs to ask the correct question in order for the feedback to be effective. This is not only important from the teacher's perspective, but also for rendering a positive effect on the student learning experience. One of the aspects of the lectureLess system is that it provides timely, accurate feedback to the teacher on what techniques work and which do not.

Therefore, we set out to devise a technology-independent assessment model for gauging student learning that would ask the right questions. Since students were self-reporting their own level of learning, our principal criteria for the assessment model was familiarity and simplicity. An overly sophisticated or otherwise difficult to understand model might be overly distracting as students enter data. Complex questions, cryptic coding, or onerous reporting requirements could also interfere with their learning. We also wanted the model to keep the students' interest and not be overly boring.

We selected a model that assesses three critical dimensions of learning-motivation, comprehension and interaction. The motivation dimension represents the student's self-reported desire to learn the topic that is currently being taught by the teacher. There is much evidence to suggest that motivation is a critical ingredient to learning. This work is captured in an excellent summary by Svinicki ${ }^{21}$. In our own experience, we had success in targeting a student's motivation independently of their comprehension or immediate understanding of the material. Keeping motivation levels up, even if the direct source of motivation is not related to the course material, helps students stay engaged and learning to germinate.

The comprehension dimension represents the student's self-reported understanding of the current topic. Self-reported comprehension is not unlike perception checks or other clarification questions an teacher might ask before moving on to another topic. In our model, this comprehension is self-reported anonymously. In our current teaching environment, we've found students are unabashed in verbalizing when they are not satisfied with their comprehension levels. We expect this willingness to translate over to self-reporting comprehension with our application.

The interaction dimension represents the level of interaction between the students and the teacher at any given point in time. This is measured as the fraction of time students are talking about the class material versus the fraction of time the teacher is lecturing about the material. In our environment, we believe the ideal distribution is one skewed toward the student doing most of talking as they reflect, ask questions, collaborate and discuss the lesson's topics. Although limited periods of pure lecture are inevitable, this same ideal environment would have the teacher lecture less (thus the origin of our system's name).

Each of the assessment model dimensions are self-reported by the student using a coded Likertscale. Comprehension ranges from "I'm Lost" (0) to "I Understand" (10); Interaction ranges from "Instructor doing all the talking" (0) to "Students doing all the talking" (10); Motivation ranges from "Current topic is boring" (0) to "I'm motivated to learn this topic" (10). Ideally, we envision students assessing their own learning in each of the three dimensions for every topic 
taught in the course. A typical 50 minute lecture might feature 3-5 different topics. For example, in an introductory Systems Engineering course, a single lesson on stakeholder analysis might discuss three topics: stakeholder types, interview techniques, and survey construction. Ideally, as the teacher leads the class through each topic, students would self-report their level of motivation, comprehension, and interaction during each topic.

\section{4. lectureLess Architecture}

As shown in Figure 1, the lectureLess architecture consists of the lectureLess mobile application running on one or more student mobile devices, a cloud-based data service, and a lectureLess viewer being used by the teacher. A feedback camera is also included in the architecture.

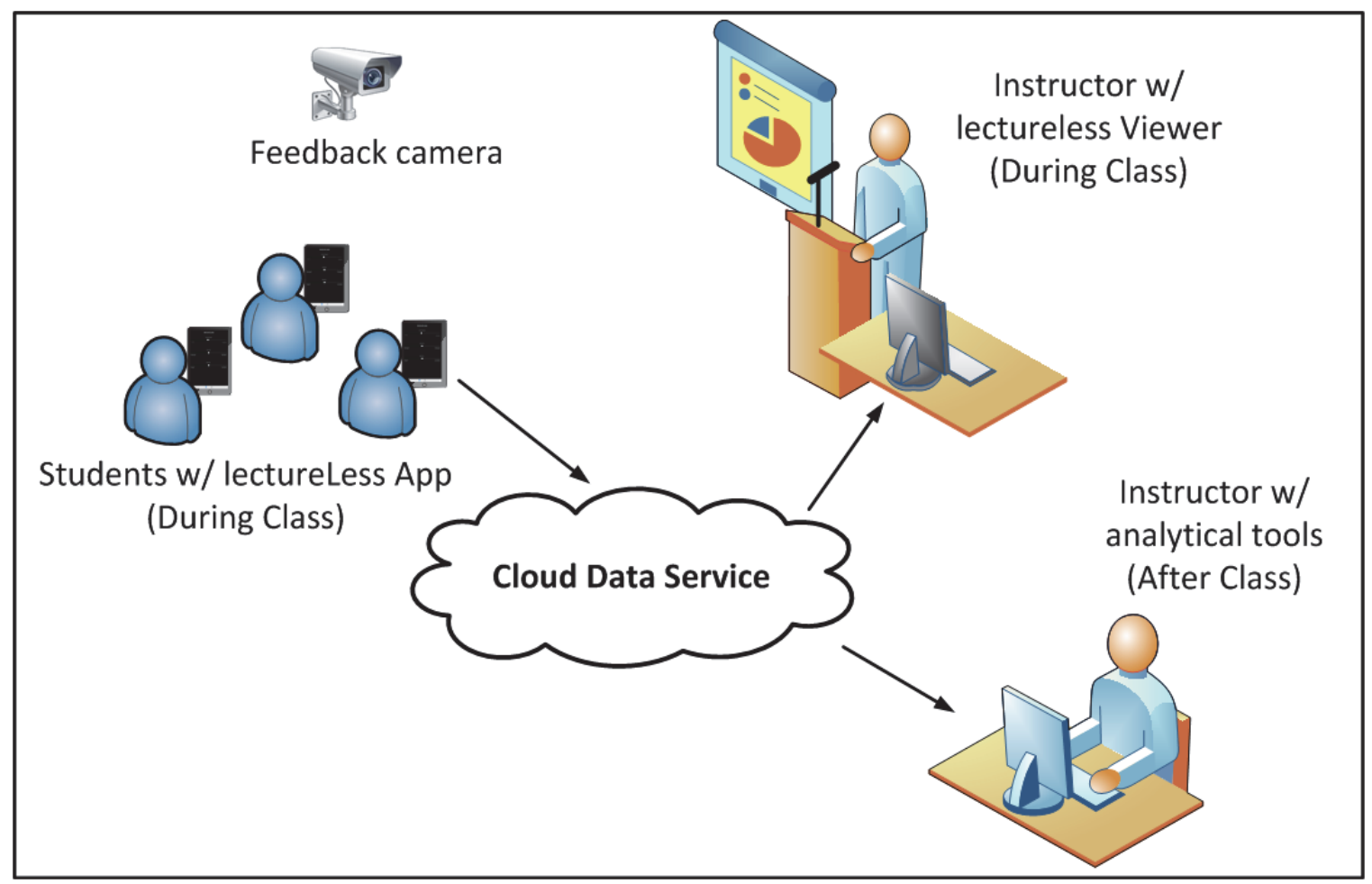

Figure 1 : lectureLess Architecture

The lectureLess Mobile Application, shown in Figure 2, is the heart of the architecture. Our current implementation of the application runs on an Apple $\mathrm{iPad}^{22}$. This application, shown in Figure 2, presents a simple graphic user interface (GUI) consisting of three horizontal sliders. Each horizontal slider is mapped to a Likert scale indicating a student's self-assessment in each of our model's dimension-comprehension, interaction, and motivation. The student can also access the settings view controller where they can specify teacher and course identification.

When a student manipulates one of the sliders, the software records the current value of each Likert scale. The application then pushes this data via the internet to a cloud-based data service for storage. Our current implementation leverages the Parse mobile cloud-service ${ }^{23}$ for this function. Parse is a "backend as a service" framework that greatly simplifies data storage and retrieval to and from many computing platforms, including mobile devices. The lectureLess application uses Parse to store Likert scale values in an internet-based datastore that is readily accessible by any number of computing platforms. 


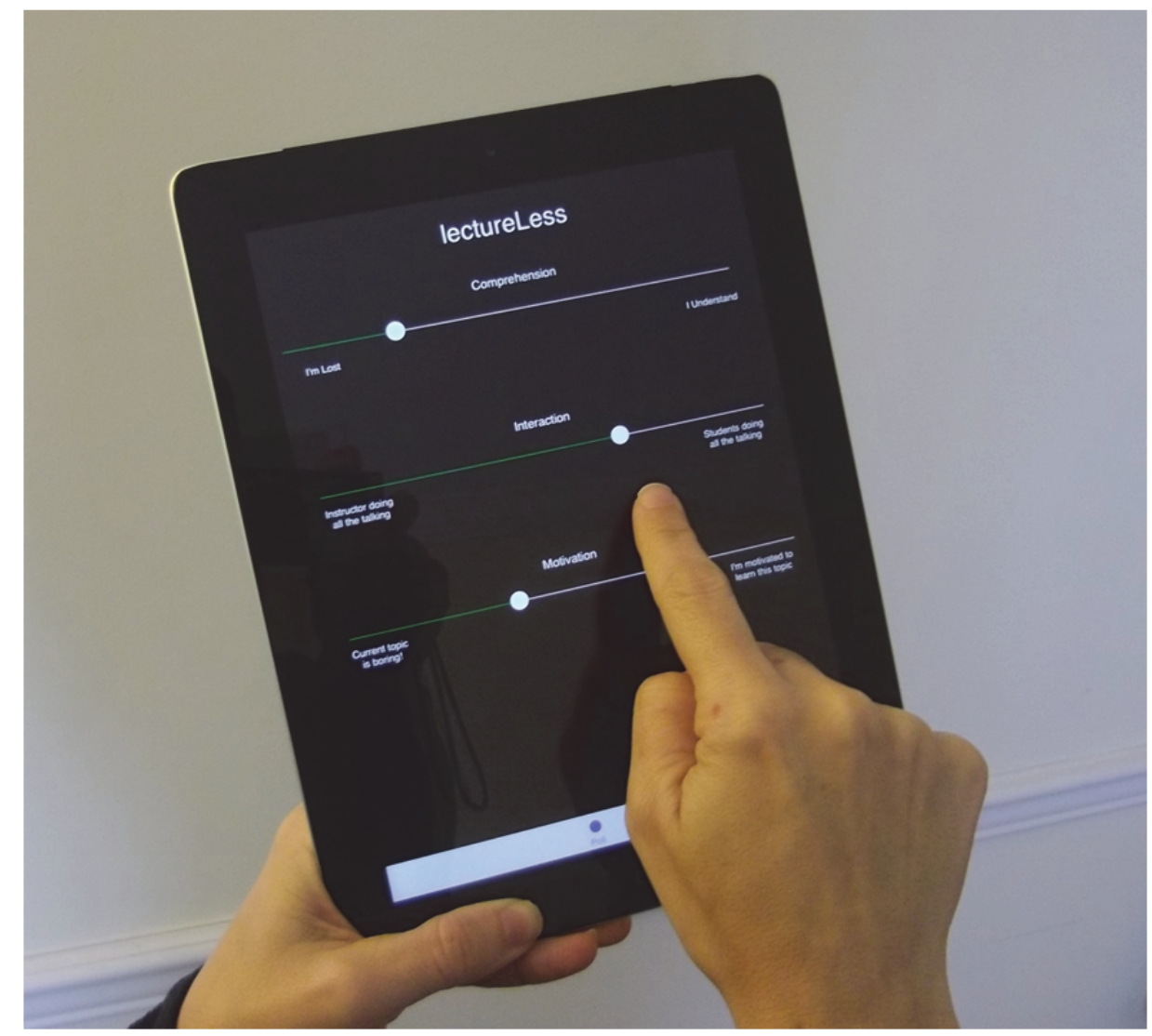

Figure 2 : lectureLess Mobile Application running on iPad

One such platform is the teacher's lectureLess Viewer. The lectureLess Viewer is a web-based application that allows the teacher to visualize, in near real-time, the assessment data being reported by the students. The application's purpose is to provide immediate feedback to the teacher as a means to improve ongoing instruction. The teacher is presented with a scrolling chart depicting recent aggregated values for each of the assessed dimensions of learning. The application depicts a three-minute time horizon of historical data. An example screenshot from the lectureLess viewer is shown in Figure 3. The time series data allows a teacher to easily track the average attainment of each learning dimension during class. If the teacher notices a decline in one of the dimensions, he or she can respond accordingly. For example, if average compression declines to a low level (as show on the right side of Figure 3 ) the teacher might stop to ask for questions.

The lectureLess Viewer utilizes server-side computer software to render the real-time visualization of student assessment data shown in Figure 3. This software aggregates the feedback from multiple students to construct a mean assessment value for each dimension. It is important to note we make two simplifying assumptions when constructing this average. First, we assume a student's current attainment of a particular learning dimension is equal to their last self-reported value, regardless of the latency of this information. In reality, we believe student attainment of each learning dimension is much more transient. However, it is also nearly impossible to track in a self-reporting paradigm. While less than ideal, our assumption relies on inflection points in the aggregate data to serve as indicators of significant change in the 
collective motivation, comprehension, and interaction of the student population. Second, in constructing an average of a subjective-value, we are assuming away differences in each student's individual interpretation of each Likert scale. While such practice is problematic in rigorous statistical analysis, we believe it is acceptable when used for purposes of real-time visualization of self-reported learning trends.

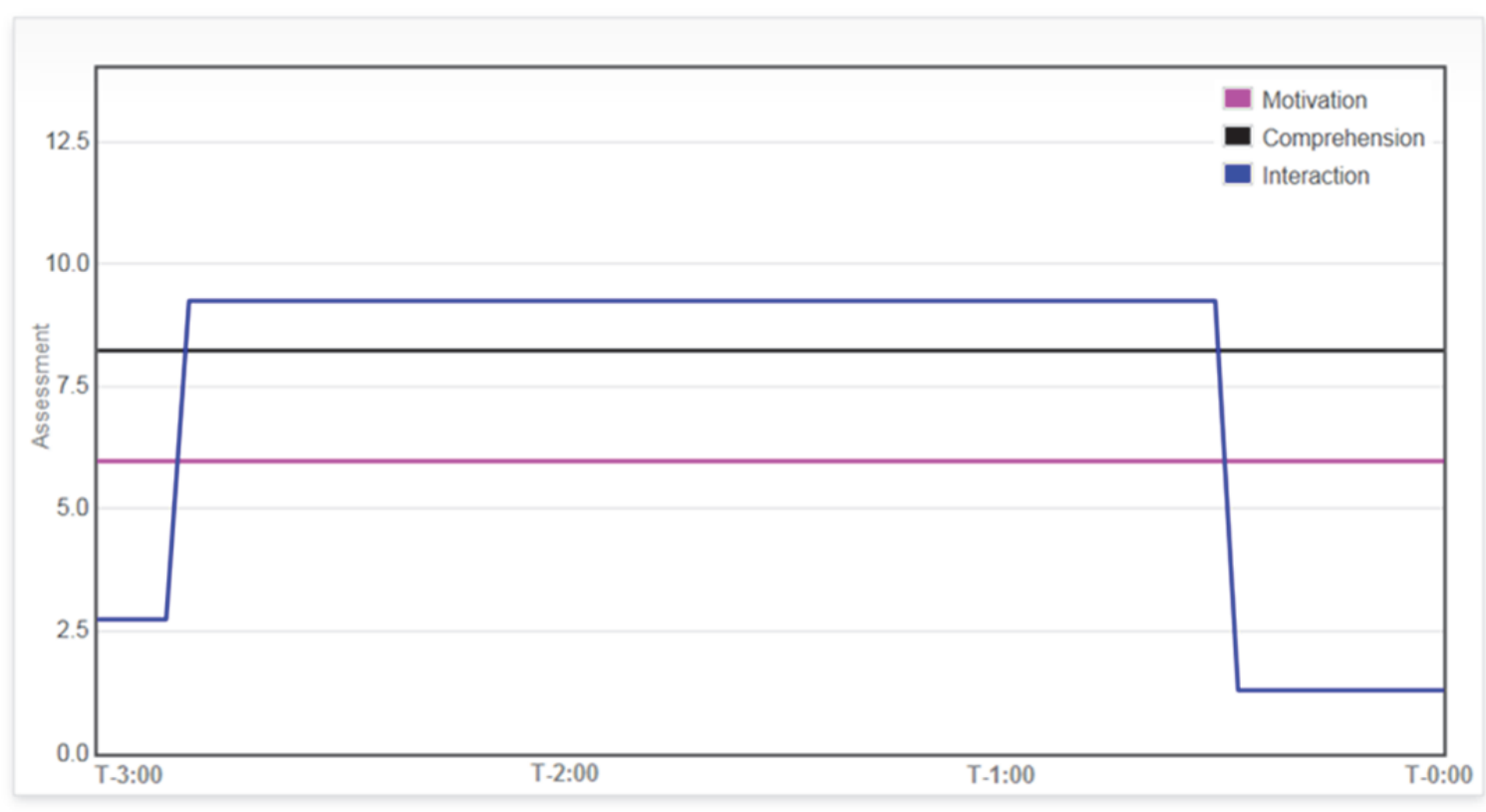

Figure 3 : Screenshot from the web-based lectureLess Viewer

For deeper analysis, the teacher can use a number of analytical tools to study the assessment data in an offline capacity. The teacher can download the assessment data as a single table using the Parse web-based dashboard. The well-formed data is easily loaded into analytical software applications such as $R$ or Excel. In this form, a teacher can carefully correlate patterns in comprehension with their lesson plans to assess how well students grasped various themes and objectives. This includes querying the data by each anonymous user to gain insights into the distribution of learning styles within each population of students.

This offline data analysis can also provide rich feedback about teaching techniques. This feedback is illuminated by correlating inflection points in each learning dimension, particularly motivation and interaction, with the execution of a particular lesson. This type of review is best accomplished by juxtaposing assessment data with video from each lesson. This can be accomplished by adding a video camera to the lectureLess architecture. The teacher positions the camera in a location with wide view of the classroom and commences recording at the start of each lesson. The video recording is manually calibrated by capturing the entry of deliberate inflection points in the assessment data feed and the video. This enables synchronization of the data and video. During offline analysis, the teacher notes a particular point of interest in the data, then advances the video to that point in time to study what was happening in the class. 


\section{Pilot Study}

We designed and executed a pilot study examining the utility and validity of the lectureLess architecture. The study consisted of undergraduate students using the lectureLess application in two different engineering courses taught by two different teachers. The first course (Course A) was a simulation elective consisting of $17 \times$ seniors ( $\sim 20$ yrs of age; 1 female, 16 male) enrolled in either engineering or operations research. The second course (Course B) was a project management course consisting of $16 \times$ seniors ( $\sim 20$ yrs age; 2 female; 14 male) enrolled in one of our institution's engineering programs. Two students were enrolled in both courses. The pilot study was blocked into 5 sessions-two administered in Course A, and three administered in Course B. These sessions were scheduled in the middle to latter half of the semester. The sessions were selected to coincide with lecture-based lessons delivered in standard classrooms because such sessions typically feature a denser set of objectives needing assessment than are found in lab sessions. Each session lasted 50 minutes and was videotaped from start to finish.

At the beginning of the study, each course's teacher described the purpose and administration of the study and instructed students how to download and install the lectureLess mobile application. Students were enlisted on a volunteer basis and participation was completely anonymous. Students self-selected into each session and no efforts were made to incentivize participation. Student participation was generally open over the entire period; however, in some cases students may have been asked to devote undivided attention to a certain classroom activity. Students at our university are given iPads as part of their overall educational experience, thus every student was afforded the opportunity to participate. The teacher brought extra fully-charged iPads to each session to accommodate students who forgot their tablets or experienced technical issues.

Table 1 depicts the participation summary for our study. The study logged 528 self-reported changes to learning dimensions across all blocks. On average, participating students logged 17.4 assessments per session, at a rate of one update every 2.7 minutes. On average, participants logged 32.4 comprehension updates, 33.4 motivation updates, and 39.8 interaction updates. Because it is impossible to simultaneously manipulate more than one slider in the lectureLess application, totals in each category can be considered mutually exclusive across learning dimensions. A three-way analysis of variance on the number of updates by dimension (comprehension, motivation, interaction) failed to find evidence of significant differences in the mean updates per session $\left(F_{(2,12)}=0.06, p=0.93\right)$.

\section{Table 1 : Study Participation Summary}

\begin{tabular}{|c|c|c|c|c|c|c|c|c|}
\hline \multirow{2}{*}{ Session } & \multirow{2}{*}{ Course } & \multirow{2}{*}{$\begin{array}{c}\text { Number } \\
\text { Participants }\end{array}$} & \multicolumn{4}{|c|}{ Number of as s es s ment updates } & \multirow{2}{*}{$\begin{array}{l}\text { Mean number } \\
\text { updates/student }\end{array}$} & \multirow{2}{*}{$\begin{array}{l}\text { Mean update } \\
\text { interval (min) }\end{array}$} \\
\hline & & & comprehension & motivation & interaction & total & & \\
\hline 1 & $\mathrm{~A}$ & 3 & 31 & 24 & 25 & 80 & 26.7 & 4.3 \\
\hline 2 & A & 6 & 16 & 19 & 20 & 55 & 9.2 & 1.6 \\
\hline 3 & B & 10 & 80 & 92 & 119 & 291 & 29.1 & 2.0 \\
\hline 4 & B & 3 & 10 & 7 & 12 & 29 & 9.7 & 2.6 \\
\hline 5 & $\mathrm{~B}$ & 6 & 25 & 25 & 23 & 73 & 12.2 & 2.9 \\
\hline & & Mean & 32.4 & 33.4 & 39.8 & 105.6 & 17.4 & 2.7 \\
\hline & & Sum & 162 & 167 & 199 & 528 & & \\
\hline
\end{tabular}




\section{Analysis}

After completing the study we examined what conclusions a teacher could draw from the collected data. We prepared the analysis by downloading the complete dataset from Parse and importing it into the $R$ statistical computing environment. We then organized the data into multiple time-series similar to those visualized in the lectureLess Viewer. For each study session, we constructed a separate time series for each learning dimension. This included depicting each participant's individual dimension, as well as a mean value for the dimension across all participants in the block. We then constructed plots for each of these times series; examples of which are shown in Figure 4. The plots depict the recorded assessment values as discrete points connected by interpolated lines.

We then conducted a visual inspection of each dimension's average time series in each of the 5 sessions to identify significant inflection points. We define a significant inflection point as one where the mean assessment experiences change exceeding \pm 4 on its Likert Scale within a 5 minute period. This is a heuristic definition based on our collective experience and our unqualified estimate of variance exhibited across all sessions and observations. Where necessary, we examined the underlying individual participant assessments to provide further confirmation of the inflection point. Several examples are shown in Figure 5. We noted 11 significant inflection points across the five sessions. Next, we began reviewing the corresponding video for each of these points to observe what was happening in the classroom and how well the teacher was teaching. We summarized our observations as a short critique of the particular teaching techniques (or pitfalls) surrounding the inflection point. For example, in Session 4, we noted an inflection point at the 10 minute point where the average student comprehension level dropped precipitously. This point is depicted in Figure 5 (red arrow overlaid on the third chart from the top). Upon viewing the video, we noted the teacher had just started discussing estimation convention-a critical concept in project management. However, several factors contributed to a decrease in student comprehension. First, the teacher started the discussion with an abstract example of estimating a generic \$8 million dollar budget. Upon reflection, the teacher might have benefitted from citing a more specific example from an actual project to help students grasp the magnitude of the budget. Second, the video revealed the teacher writing on a small section of chalkboard that limited legibility and was not readily visible to all students during the discussion. It was also noted that the overhead projector, which takes up a majority of the classrooms frontage, was still presenting the course title slide. This resource might have served better by augmenting the discussion on estimation convention. Table 2 summarizes our critique of the significant inflection points. 


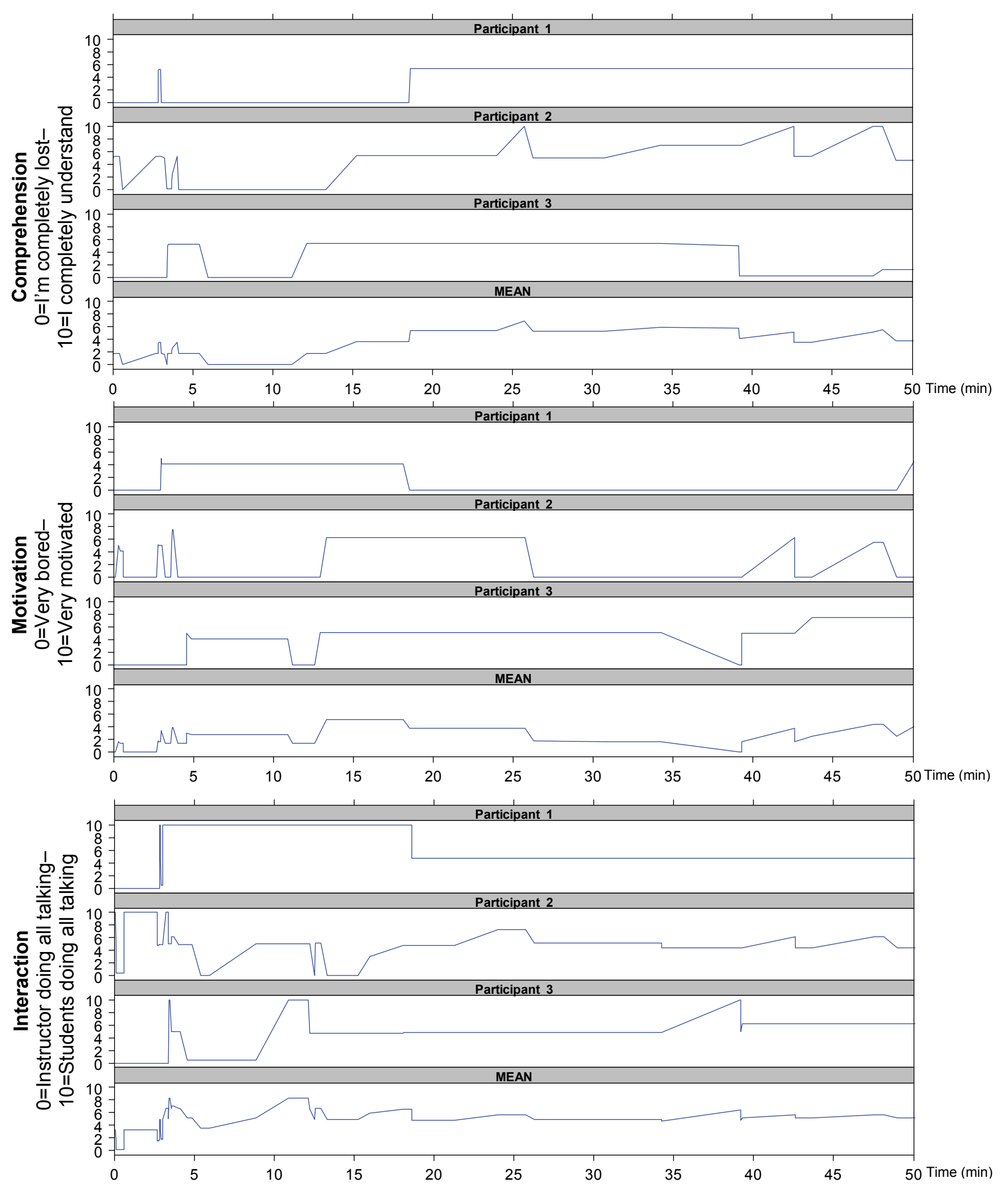

Figure 4 : Analytical plots from Session 4. The plots depict assessment data across three learning dimensions as reported by three subjects. The bottom plot in each stack depicts the mean assessment for each dimension. 


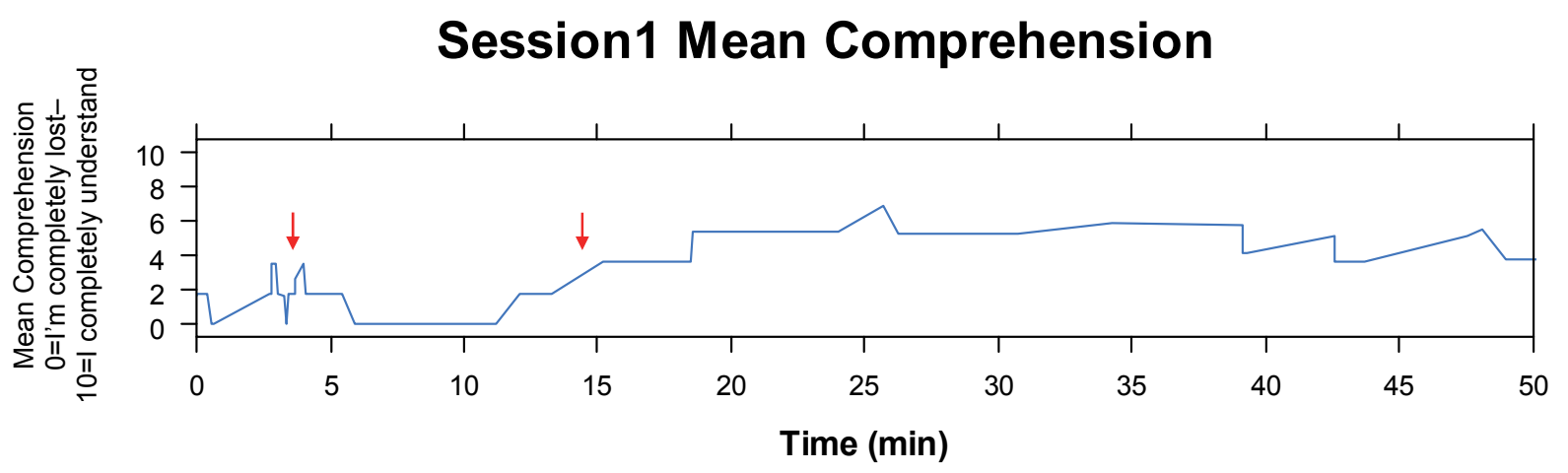

Session1 Mean Motivation
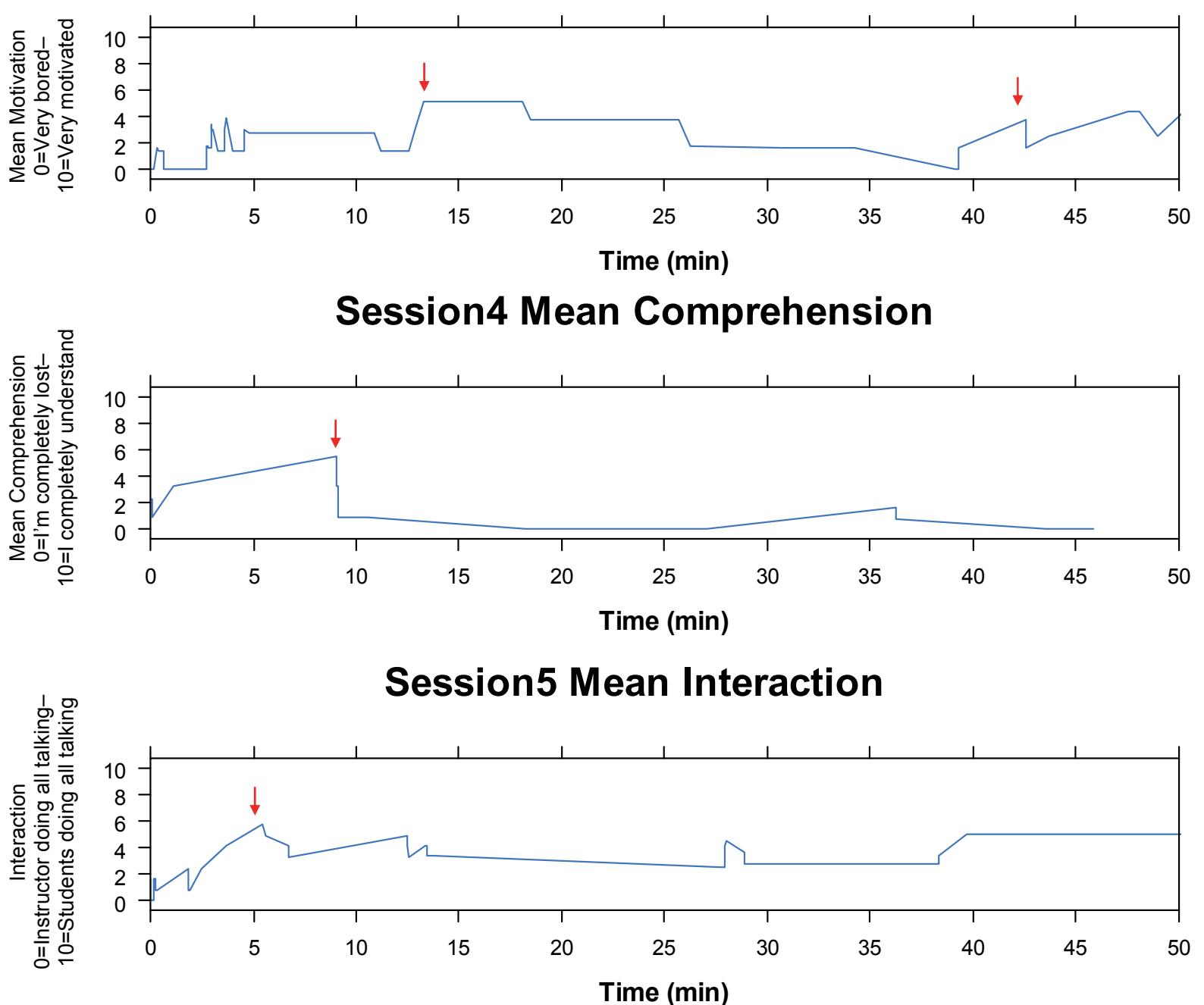

Figure 5 : Examples of significant inflection points. Red arrows depict where mean assessment in each dimension experienced a change greater than \pm 4 within 5 minutes. 
Table 2 : Significant inflection points and their critique

\begin{tabular}{|c|c|c|c|c|}
\hline Session & Dimension & $\begin{array}{l}\text { Elapsed } \\
\text { Time } \\
\text { (min) }\end{array}$ & Change & Teacher critique \\
\hline 1 & Interaction & 4 & Increase & Initial teacher-student banter at the start of class \\
\hline 1 & Comprehension & 3 & Decrease & $\begin{array}{l}\text { Initial confusion when talking in the abstract; } \\
\text { Consider kicking off with overall unifying example }\end{array}$ \\
\hline 1 & Comprehension & 14 & Increase & $\begin{array}{l}\text { Teacher began working a specific example on the } \\
\text { board }\end{array}$ \\
\hline 1 & Motivation & 13 & Increase & $\begin{array}{l}\text { Using example germane to the student's life } \\
\text { experience }\end{array}$ \\
\hline 2 & Comprehension & 3 & Decrease & $\begin{array}{l}\text { Student presentation; read notes from text as } \\
\text { opposed to instructing class }\end{array}$ \\
\hline 2 & Comprehension & 28 & Increase & $\begin{array}{l}\text { Changed subject; Good integration of real world } \\
\text { example, projected media, and board notes }\end{array}$ \\
\hline 4 & Interaction & 2 & Increase & Teacher calling on individuals during review \\
\hline 4 & Interaction & 10 & Increase & $\begin{array}{l}\text { Teacher continually bringing students in to } \\
\text { provide definitions and personal examples }\end{array}$ \\
\hline 4 & Comprehension & 10 & Decrease & $\begin{array}{l}\text { Teacher used an abstract example; Writing on } \\
\text { board where all students cannot see; Use } \\
\text { projector to help! }\end{array}$ \\
\hline 5 & Interaction & 5 & Increase & $\begin{array}{l}\text { Teacher invoked a personal example and asked } \\
\text { advice from the class about his son }\end{array}$ \\
\hline 5 & Comprehension & 5 & Increase & $\begin{array}{l}\text { Teacher split class up and had groups work } \\
\text { example problems }\end{array}$ \\
\hline
\end{tabular}

\section{Discussion}

We were pleased that students successfully used the lectureLess application to record their selfassessment of various learning dimensions during class. As a prototype, the system architecture worked well, with students seamlessly pushing data to a centralized data repository where it could later be pulled by the teacher. There was no evidence of any dropped or superfluous data which indicates the design is acceptable and scalable.

We were pleasantly surprised at the overall level of student participation as evidenced in their average reporting rate of once every 2.7 minutes. When examining the assessment trajectories, we were intrigued by the patterns in the data. We did not expect to detect noticeable trends given the students' diverse learning styles and our small samples of participants (our largest 
session had only 10 participants). However, aggregating the time series across the students in each session did suggest meaningful trends that we were also able to collaborate when observing the sessions on video tape. These trends were in turn helpful in focusing a teacher's own critique of each session. Without the student's synchronized assessment, or a third-party observer, a teacher's own assessment of their video is arbitrary and potentially susceptible to biases. However, the student's self-assessment provides an important and difficult to estimate perspective on a teacher's approach to teaching. For this reason we feel that the juxtaposition of student self-assessment with video is a powerful combination worthy of additional development.

There is much work to be done in order to improve our approach and build on our initial findings. First, we plan to automate the detection of significant inflection points in the assessment trajectories. This will speed the analytical process and allow for parameterized control of what is and isn't considered a significant inflection point. These improvements will include incorporating more rigorous statistical tests to control for the subjective nature of the Likert scale values and the small sample sizes. We also hope to provide a means to automate a side-by-side view of the trajectory values with the video tape. In our current implementation, this is done manually which is error prone and does not scale well.

Upon improving our analytical tools, we hope to enlist the help of third-party observers to critique the video segments in and around each inflection point. Ideally, this would be a twostage study with a population of observers viewing the classroom video segments (and control segments) for student inflection points and conducting their own evaluation using established teaching rubrics. This data could be correlated with the students' self-assessment to verify the integrity of our underlying learning model. This study could also feature an expert teaching observer who sits in each session and uses the lectureLess app to log their own observations.

We did not experiment with the lectureLess Viewer as a source of real-time feedback during our pilot test. This was due to an absence of a workable solution for presenting the lectureLess data during the class (e.g., via an extra monitor). In the future, we hope to field a mobile version of the lectureLess viewer that would allow for discrete viewing on a smaller smartphone. Our plans for improving the lectureLess Viewer also include incorporating some of the functionality we manually conducted during our off-line data analysis. This must include an intuitive user interface and visualization techniques as to not burden or distract the teacher during the lesson.

There are a number of operational challenges that also must be addressed in future work. The first of these challenges centers on how to incentivize a student's regular use of the lectureLess application. In our study, student interest was implicitly high given the novelty of the study and use of the iPad. More work is needed to sustain interest in self-assessment in the long term. Also, the small sample size of self-selecting participants limits the statistical significance of the system's feedback. We hope that incentivizing the use of lectureLess across a broad range of learners will improve our sample. However, increasing the use of the application could potentially introduce a second challenge. Because other mobile device applications can serve as tempting diversions for students, future incentives to use lectureLess also need controls to keep students focused on the lesson. One potential solution we are examining is incorporating the real-time assessment abilities of lectureLess into an application that delivers dynamic content to augment an ongoing classroom lesson. This dynamic content could be tailored to each student based on their continually evolving self-assessment. 


\section{Conclusion}

In this paper, we introduced a mobile application used to effortlessly record, in real-time, a student's assessment of their own learning. The application functions as part of a larger architecture we designed to allow a teacher to monitor learning during class and gain even deeper insights during subsequent offline analysis. A pilot study revealed our architecture was able to successfully record and support analysis of our students' self-reported learning assessments. Notably, the architecture serves as a useful tool for spotting trends in student learning that, when combined with video of a class, can be a powerful critique.

\section{References}

1 Bloom, Benjamin S., Engelhart, M. D., Furst, Edward J., Hill, Walker H. and Krathwohl, David R. (1956) 'Taxonomy of educational objectives: Handbook I: Cognitive domain'. New York: David McKay, 19, p. 56.

2 Perry, William G (1999) Forms of ethical and intellectual development in the college years: A scheme, Jossey-Bass Publishers.

3 Lenhart, Amanda, Purcell, Kristen, Smith, Aaron and Zickuhr, Kathryn (2010) Social media \& mobile internet use among teens and young adults, Pew Internet \& American life Project.

4 Yardi, Sarita (2008) 'Whispers in the classroom'. Digital youth, innovation, and the unexpected, pp. 143-164.

5 Costa, Cristina, Beham, Guenter, Reinhardt, Wolfgang and Sillaots, Martin (2008)

'Microblogging in technology enhanced learning: A use-case inspection of PPE summer school 2008', in Proceedings of the 2nd SIRTEL'08 Workshop on Social Information Retrieval for Technology Enhanced Learning,

6 Pintrich, Paul R. and De Groot, Elisabeth V. (1990) 'Motivational and self-regulated learning components of classroom academic performance.' Journal of educational psychology, 82(1), p. 33.

7 Angelo, Thomas A. and Cross, K. Patricia (1993) 'Classroom assessment techniques'. Ann Arbor, MI: National Center for Research to Improve Postsecondary Teaching and Learning.

8 Fink, L. Dee (1995) 'Evaluating your own teaching', in P. Seldin (ed.), Improving College Teaching, Anker.

9 Fink, Dee (2008) 'Evaluating teaching: A new approach to an old problem'. To Improve the Academy, 26, pp. 3-21. 
10 Kay, Robin H. and LeSage, Ann (2009) 'Examining the benefits and challenges of using audience response systems: A review of the literature'. Computers \& Education, 53(3), pp. 819-827.

11 Fies, Carmen and Marshall, Jill (2006) 'Classroom response systems: A review of the literature'. Journal of Science Education and Technology, 15(1), pp. 101-109.

12 Caldwell, Jane E. (2007) 'Clickers in the large classroom: current research and bestpractice tips'. CBE-Life Sciences Education, 6(1), pp. 9-20.

13 Stav, John, Nielsen, Kjetil, Hansen-Nygård, Gabrielle and Thorseth, Trond (2010) 'Experiences obtained with integration of student response systems for iPod Touch and iPhone into e-learning environments'. Electronic Journal of e-Learning, 8(2), pp. 179190.

14 Pohl, Alexander, Gehlen-Baum, Vera and Bry, François (2011) 'Introducing Backstage-a digital backchannel for large class lectures'. Interactive Technology and Smart Education, 8(3), pp. 186-200.

15 Bry, François, Gehlen-Baum, Vera and Pohl, Alexander (2011) 'Promoting awareness and participation in large class lectures: The digital backchannel backstage', in Proceedings of the IADIS International Conference e-Society,pp. 27-34.

16 Highet, Gilbert (1961) The art of teaching, New York, Vintage Books.

17 Lowman, Joseph (1995) Mastering the techniques of teaching, Jossey-Bass, Inc.

18 Naftulin, Donald H., Ware Jr, John E. and Donnelly, Frank A. (1973) 'The Doctor Fox lecture: A paradigm of educational seduction'. Academic Medicine, 48(7), pp. 630-5.

19 Ware Jr, John E. and Williams, Reed G. (1975) 'The Dr. Fox effect: A study of lecturer effectiveness and ratings of instruction'. Academic Medicine, 50(2), pp. 149-56.

20 Bain, Ken (2011) What the best college teachers do, Harvard University Press.

21 Svinicki, Marilla D. (2004) Learning and motivation in the postsecondary classroom, Anker Publishing Company.

22 lectureLess (2014) iTunes App Store. [online] Available from: https://itunes.apple.com/us/app/lectureless/id722163491?mt=8 (Accessed 4 January 2014)

23 Parse (2014) [online] Available from: https://www.parse.com (Accessed 5 January 2014) 